\title{
Coping with Uncertainty in River Management: Challenges and Ways Forward
}

\author{
J. J. Warmink ${ }^{1}$ • M. Brugnach ${ }^{1} \cdot$ J. Vinke-de Kruijf ${ }^{2}$. \\ R. M. J. Schielen ${ }^{1,3}$ • D. C. M. Augustijn ${ }^{1}$
}

Received: 1 March 2017 / Accepted: 21 June 2017 /

Published online: 6 July 2017

(C) The Author(s) 2017. This article is an open access publication

\begin{abstract}
Coping with uncertainties is inherent to river management planning and policymaking. Yet, policymakers often perceive uncertainty as a complicating factor. We examine the challenges faced by policymakers when coping with uncertainties and provide an action perspective on how to best cope with these challenges to inform the policy debate. Integrating social and natural scientist's perspectives on uncertainties and learning theories, we present a holistic, management perspective for coping with uncertainty. Based on a literature review about uncertainty concepts, strategies and learning, we identify three challenges in current river management: balancing social and technical uncertainties, being conservative and avoiding to end up a lock-in situation. We then provide a step-wise strategy and concrete actions for policymakers, which are illustrated with several examples. We conclude that coping with uncertainty may require paradigm shifts that can only be achieved through organisational learning. This, we claim, requires reflection, learning and flexibility of policymakers and their organisation.
\end{abstract}

Keywords Policymaking -Uncertainty·Ambiguity· Rivermanagement - Adaptivemanagement

\section{Introduction}

Policymakers responsible for river management have multiple, sometimes contradicting tasks. They must develop policies for the long term, knowing that the opposition is potentially large and uncertainty is a willing argument to halt their initiatives. In their policies, they need to find

\section{J. J. Warmink}

j.j.warmink@utwente.nl

1 Department of Water Engineering and Management, University of Twente, P.O.Box 217, 7500AE Enschede, The Netherlands

2 Department of Construction Engineering and Management, University of Twente, P.O.Box 217, 7500AE Enschede, The Netherlands

3 Rijkswaterstaat, P.O.Box 2232, 3500GE Utrecht, The Netherlands 
a balance between the needs of different actors and multiple river functions, such as navigation, drinking water supply, nature development, recreation and flood risk. These functions are interrelated and concern multiple and diverse stakeholders and uncertainties, making river management a highly complex task. Furthermore, river management policies are developed and implemented for different scales and at different governance levels. The responsibility for implementing measures and executing maintenance is often devolved to local or regional authorities whereas policy frameworks and regulations are enacted at a national or supranational level. In this paper, we will examine uncertainty management on the development and implementation of policies for large rivers of national importance by policymakers operating at the national or sub-national level.

While the scholarly literature on uncertainty management is burgeoning (e.g. Walker et al. 2003, 2013; Pahl-Wostl et al. 2007; Dessai and Hulme 2007; Brugnach et al. 2008; Hommes et al. 2009a; Warmink et al. 2010), scholars still fall short in addressing the complexity of policy processes associated with river management and governance. This happens for reasons that are both conceptual and practical. On the one hand, there is a tendency to focus on strategies to cope with uncertainty targeting specific uncertainty types, often discounting that the unknowns associated with river systems are many, interrelated and involving social, biophysical and technical aspects of the river system. On the other hand, attempts to address uncertainties in connection to the socio-institutional system still remain elusive in concrete actions (e.g. Walters 2007). Uncertainty management strategies are often imposed by governments, but their implementation remains challenging (Allan and Curtis 2005; Walters 2007; Failing et al. 2013). Implementation is hampered by governance issues, such as, policymakers being unwilling to admit and embrace uncertainties when making policy choices (Walters 2007) and a lack of government funding to support learning from monitoring programs for an extended period of time (Allan and Curtis 2005; Walters 2007). Our aim is to combine theories of uncertainty and organisational learning to show how social learning enables better coping with uncertainty in complex problems like river management and policy making. We add to this literature by providing concrete action perspectives for policymakers and present examples to show its potential. We build upon earlier studies that combine insights from natural and social sciences and call for a more holistic perspective on uncertainty management (e.g. Pahl-Wostl et al. 2007; Ascough et al. 2008; Brugnach et al. 2008; Hommes et al. 2009a; Van der Keur et al. 2008; Van den Hoek et al. 2014).

The paper starts with a review of the literature with regard to uncertainty typologies, strategies and paradigms to cope with uncertainties and the potential of learning and organisational change (section 2). Section 3 presents three key challenges faced by policymakers when coping with uncertainty in river management. In section 4 , we provide the way forward: implementing change in the policymaking process and illustrate strategies and action perspectives with concrete examples to improve uncertainty management. Section 5 presents the conclusions.

\section{Uncertainty in the Policymaking Process, a Review}

\subsection{Characterizing Uncertainty}

To conceptualize and distinguish between different forms of uncertainty, a wide range of uncertainty typologies has been developed by natural and engineering scientists as well as social scientists. Uncertainty typologies are useful to frame uncertainties, aid communication 
and can instruct policymakers about how to deal with different types of uncertainty (Refsgaard et al. 2007; Brugnach et al. 2008; Stirling 2010; Bond et al. 2015). In natural sciences and engineering, uncertainty is commonly understood to be caused by either a lack of information (epistemic uncertainty) or inherent random variation (ontological uncertainty) associated with, for example, the river system (e.g. Van Asselt and Rotmans 2002; Walker et al. 2003). Typically, the response to epistemic uncertainty is to reduce the uncertainty by gathering and processing more information (Walker et al. 2013). As ontological uncertainty is inherently irreducible, it is generally elucidated by statistical analysis (Walker et al. 2013).

Accounting for the socio-institutional context in which management and policymaking takes place, several authors have extended this notion of uncertainty to also include uncertainties associated with the social system. Van Asselt and Rotmans (1996) took into account the variety of perspectives of decision makers in relation to uncertainty. Building upon insights from the literature on problem structuring (Hisschemöller and Hoppe 2001), Hommes et al. (2009a, b) link policy controversies to actor perceptions and uncertainty to knowledge. Along similar lines, Merz et al. (2015) distinguish between system complexity and cognitive bias to explain the potential for surprise. Acknowledging the social processes underlying decision making, and considering the multiple valid ways in which problems and solutions are framed in multi-actor decision settings, Brugnach et al. (2008) identify ambiguity as a third type of uncertainty, next to epistemic and ontological uncertainty. They define ambiguity as the degree of confusion that exists among actors in a group (e.g. stakeholders) due to the presence of multiple, valid, and sometimes conflicting, interpretations (Weick et al. 2005) rather than, how much is known or not known about a system. Building on these concepts, Van den Hoek et al. (2014) shows that epistemic and ontological uncertainty and ambiguity are not independent from each other, but are often interrelated, meaning that what is known (or not known) about a system is influenced by the framings through which issues or problems are comprehended. Building upon this literature, we conceive uncertainties in river management as related to deficits of knowledge (possibly epistemic or ontological in nature) and to the ambiguity resulting from the presence of multiple, and valid, ways of framing problems and solutions.

\subsection{Coping with Uncertainty: Strategies and Paradigms}

One of the paradigms that has been promoted for more than three decades as a way to cope with uncertainty is adaptive river management (e.g. Pahl-Wostl et al. 2007; Allan et al. 2013). Adaptive management involves learning from the outcomes of previous actions. Hence, from an adaptive management perspective, suitable strategies to cope with uncertainties are not necessarily limited to reduce uncertainty (Allan and Curtis 2005; Walters 2007), they also incorporate social learning (Pahl-Wostl et al. 2007; Allan et al. 2008; Brugnach et al. 2011). However, while applying adaptive management proposes 'learning by doing', we observe that in practice, it is an illusion to state that a management paradigm is completely adaptive. Once certain choices are made, part of the adaptiveness character of a strategy vanishes. The essential point is to make decisions that leave opportunities for flexibility, rather than to make decisions that lead to a (technical or governmental) lock-in.

Most uncertainty management strategies recognize the importance of incorporating multiple stakeholders' perspectives (Wyborn 2015; Van der Keur et al. 2016) and learning (PahlWostl et al. 2007; Allan et al. 2008; Collins and Ison 2009) as well as the need for flexibility and the capacity for changing goals in the policymaking process in response to new knowledge (Thissen et al. 2017). This implies that, if the policy does not work, it needs to be changed. 
Such changes may not only require changes in infrastructure (e.g. the reinforcement of an existing dike) but also changes in the organization of the policy process and the governance structure (Pahl-Wostl 2009; Allan et al. 2013).

\subsection{Learning and Organisational Change}

Coping with uncertainties may require actions that extend from simple improvements of data, to reframing of problems and solutions or changing the structural governance context. To understand the learning processes associated with such changes, we propose to extend the concept of multi-loop learning in policymaking to uncertainty management. Pahl-Wostl et al. (2007) and Pahl-Wostl (2009) build upon Argyris and Schön (1978) and Hargrove (2002) to distinguish between three learning loops that can be linked to changes in three different aspects of the policymaking process: actions, frames and context (Fig. 1). Single-loop learning refers to situations in which performance is improved by refining actions and making incremental improvements to established routines. Double-loop learning implies that underlying values and assumptions are questioned and involves reframing. Triple-loop learning involves structural changes in the governance regime. Like policymaking, coping with uncertainties is an iterative and stepwise process during which constraints and boundaries are met. When changing actions and frames is no longer sufficient, large-scale governance changes (referred to as "transformations") are required to effectively cope with the uncertainties.

When coping with uncertainties, first-loop learning may involve that uncertainties are reduced or eliminated by including new or better information. This can be achieved by conducting more research, collecting additional data or improving the assessment of uncertainties (e.g. confidence intervals). However, people's frames of reference, context and problem definitions are not questioned. This first-loop comprises, for example, that novel scientific tools are defined as the new standard, thereby reducing epistemic uncertainty, and improved methods and more observations reduce the ontological uncertainties. Also, better procedures can be effectuated to enhance the dialogue between policy and public. An example of this loop is that policy outcomes are monitored and actions are changed accordingly.

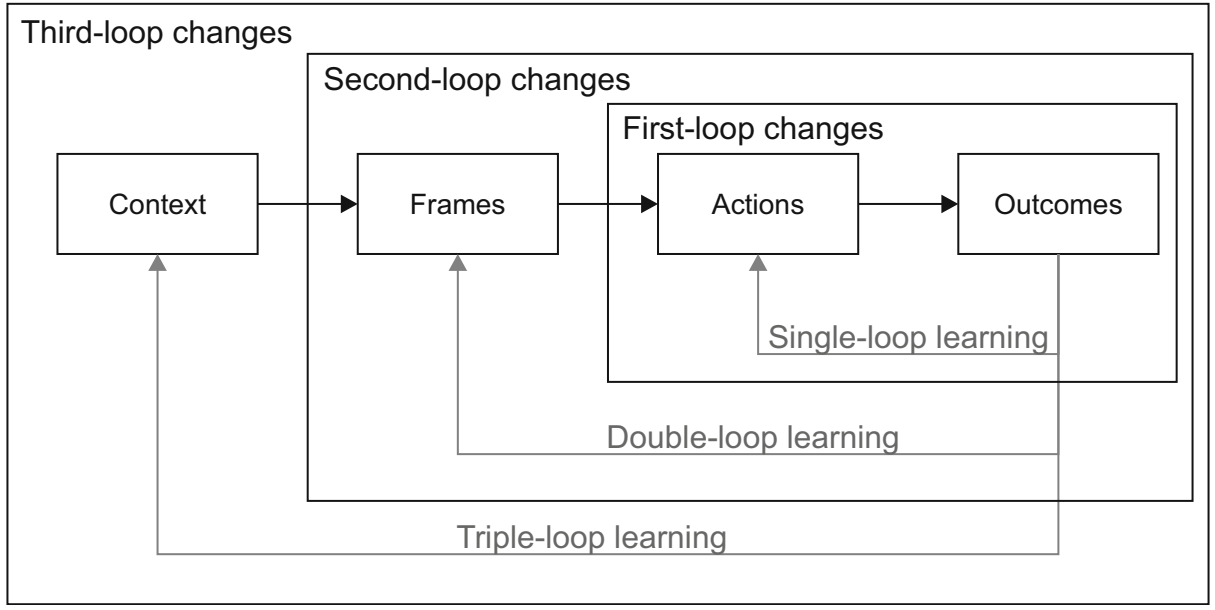

Fig. 1 Sequence of organisational changes and learning cycles in policymaking processes (modified after Hargrove 2002 and Pahl-Wostl 2009) 
Second-loop changes may be necessary in case first-loop changes do not provide an adequate response to uncertainty. For example, when the solution to a problem stretches beyond improving models and acquiring more data (Warmink et al. 2010), the underlying assumptions of problem definitions and management strategies may need to be reframed. For example, the set of procedures needs to be critically reviewed, which involves a reflection on goals. Improvement is achieved by experimenting with innovative strategies and new kinds of measures (Pahl-Wostl 2009).

Third-loop changes refer to the transformation of the structural context, including changes to factors that determine the frame of reference of policymakers and the governance structure. This requires a fundamental change in the perceptions and mind-sets of actors involved (Lawrence et al. 2013) as well as changes in underlying norms and values and the governance structure (Pahl-Wostl 2009). For example, a third-loop change may imply that a flood protection policy is changed from preventing floods to accepting floods under certain conditions and prioritize evacuation strategies. It may also imply changing responsibilities, for example, that flood protection in cases of (extreme) discharge is no longer a government responsibility only, but becomes the shared responsibility of the public by means of insurance, local authorities and democratic decisions. These changes can be quite fundamental since they can be perceived as unacceptable by policymakers and require major changes in governmental responsibilities, perceptions and management paradigms.

\section{Challenges in Coping with Uncertainty in River Management}

Uncertainty is often perceived by policymakers to complicate decision making. Based on the literature review in section 2, we identified three common challenges in current river management practice: 1) balancing social and technical uncertainties, 2) being too conservative when coping with uncertainty, which may result in 3) an unwanted lock-in situation.

\subsection{Challenge 1: Balancing Social and Technical Uncertainties}

Uncertainty is inherent to policymaking. However, uncertainty analysis is often considered a burden in, for example, river management where policymakers often perceive uncertainty analysis as a lot of (unnecessary) work (Pappenberger and Beven 2006). In practice, uncertainty is therefore often perceived as unwanted, resulting in "uncertainty-averse" reactions. A typical response of policymakers is to reduce, and preferably eliminate, uncertainty. As a result, they are paying either too much or too little attention to specific types of uncertainty.

At first sight, policymakers may want to reduce technical uncertainty by demanding more information (Koppenjan and Klijn 2004). However, a strategy of reducing uncertainties may be counterproductive when uncertainties cannot be reduced, such as in cases of ontological uncertainty. Theoretically, epistemic uncertainty can be reduced, but only when sufficient time and means are available (Hommes et al. 2009a) and depending on the type and source of information that is lacking (Van der Keur et al. 2008).

On the other hand, new information might also increase uncertainty, because it reveals uncertainties that were previously unknown (Hommes et al. 2009a). Too much focus on technical uncertainties might result in the creation of superfluous knowledge (Van de Riet 2003) that is irrelevant to the policy process. At the same time, creating a knowledge base that is scientifically valid is essential, since too much focus on the process (and on social 
uncertainty) may risk resulting in what is sometimes called 'negotiated nonsense' (Van de Riet 2003; Koppenjan and Klijn 2004; Hommes et al. 2009a). Therefore, coping with uncertainties implies balancing between process (dealing with ambiguities) and content (dealing with uncertain or a lack of knowledge).

A case of paying too much attention to technical uncertainty is presented in Hommes et al. (2009a). They examined the process in which impacts of the extension of the Mainport Rotterdam in the Netherlands on the local ecology were assessed. They particularly investigated how stakeholders' perceptions were dealt with and how knowledge was used in this decision-making process. They showed that the process had a strong focus on reducing technical uncertainty, which was addressed by gathering information and counter-expertise. After finishing the impact assessment, there was still disagreement between experts and lack of trust by the stakeholders about the final assessment reports. Since diverging stakeholder perspectives were not addressed, the process resulted in superfluous knowledge.

A case in which actors produced knowledge that was partly seen as negotiated nonsense and partly as irrelevant is provided by a "Room for the River" project in Romania (Vinke-de Kruijf et al. 2012, 2015). In the project, a team of Dutch and Romanian experts organized an interactive and participatory process that dealt with flood risk management alongside other development issues. The process helped to reveal ambiguities, i.e. that stakeholders framed the problems in the project area in different, often conflicting ways. The project team successfully dealt with these ambiguities by integrating the diverse perspectives and ideas of participants into three different directions for solutions (so-called design concepts). When presented to a wider audience, the credibility of the project knowledge was questioned by several Romanian experts who had not been engaged in the knowledge production process. National actors who could decide upon and provide financial resources for the implementation of solutions were indecisive. As a result, the project generated knowledge that was highly valuable to the participants (mostly regional actors) but not legitimate, credible and salient to key experts and policymakers.

In both examples, the knowledge production process neither engaged all relevant actors nor their knowledge and, as a result, social uncertainty was poorly addressed. When dealing with complex, uncertain policymaking problems, De Bruijn and Leijten (2007) state that "all types of information are basically ambiguous or contested since underlying facts and normative standards are controversial". Therefore, both policymakers and scientists alike should pay more attention to neglected areas of uncertainty (Stirling 2010). Not balancing the social and technical uncertainties could mean that we limit our ability to take corrective action in the future and end up in situations that could have been avoided (Walker et al. 2013). Conversely, the unbalance may also limit our ability to take action. Therefore, the challenge is to take into consideration both the social and technical uncertainties and address them in early project stages in a planning that would be acceptable to all stakeholders.

\subsection{Challenge 2: Being Conservative}

In river management practice, uncertainty is dealt with on a daily basis. However, not always in an optimal manner. The changing water paradigm describes that "modern" industrial societies have routinely and dramatically modified the natural system of water distribution and it notions that physical solutions continue to dominate traditional planning strategies (Gleick 2000). PahlWostl et al. (2011) define that a management paradigm refers to "a set of basic assumptions about the nature of the system to be managed, the goals of managing the system and the ways in 
which these goals can be achieved". Water management in modern industrial societies has often been characterized as a control-based strategy (Pahl-Wostl et al. 2011). Most modern industrial countries have the heritage of such a control-based management paradigm (Pahl-Wostl et al. 2007). System design was typically targeted at high predictability and controllability and uncertainties were managed by being conservative. Being conservative implies to strive for a safe decision, where there are no regrets. Malicious surprises, such as, unexpected incidents or disasters, should be avoided (Merz et al. 2015). The associated uncertainty strategy can therefore be typified as "better safe than sorry".

Very high safety standards are applied in, for example, the Netherlands (DP 2015) where floods are projected to cause enormous damage, societal disruption and loss of lives in large parts of the country. The choice of a high return period is the result of a cost-benefit analysis (IWR 2011). On top of these high flood protection standards, modern industrial countries apply safety margins to cope with uncertainty in observations and models (e.g. Eurocode). This strategy yields very safe flood protection structures, but with associated high costs.

To avoid unnecessary costs, there is a strong focus on quantification and reduction of uncertainties, mainly in the natural and technical system. This is achieved by doing more measurements and improving the quality of models. Therefore, besides being conservative, uncertainty is dealt with by gathering more data, information and knowledge with the objective of reducing the uncertainties and thereby costs. However, aiming to reduce or quantify uncertainty ignores the existence of uncertainties that cannot be reduced by gathering more data or described by using statistics (Brugnach et al. 2011). Therefore, striving for certainty of information that supports public policy, can be a waste of effort and resources. Furthermore, established routines are defined to regularly update flood-risk assessments based on new insights and knowledge, illustrating first-loop changes only. This strategy can be typified as "business as usual".

In the example above, where flood risk is based on a cost-benefit analysis, the management strategy and the way to manage uncertainty is based on the underlying idea of control of the natural and social system and processes. This control-based management stimulates being conservative as a strategy to cope with uncertainty and the feeling that uncertainties complicate policymaking.

\subsection{Challenge 3: Reaching a Lock-in Situation}

Being conservative as a strategy to cope with uncertainty may create a lock-in situation. For example, once developments behind dikes are in place, there is a public and governmental demand to maintain and protect them, and even increase the protection over time (Lawrence et al. 2013). High protection standards motivate a conservative strategy aimed at preventing floods. Being conservative leads to very strong flood defences. Therefore, floods become rare, the awareness of the public for floods is low and mitigation measures become less urgent. This increases the consequences of a flood and the potential for surprise or disasters, which in turn leads to higher protection standards. In this situation, floods become increasingly unacceptable, not only in people's stakes and perceptions, but also from a cost-benefit point of view, which results in a situation that being conservative is even more preferred. This vicious circle finally yields a lock-in situation (Tillman et al. 1999).

In a lock-in situation, paradigm shifts become increasingly difficult (Pahl-Wostl et al. 2011). This is one of the challenges for policymakers in modern industrial societies who are encouraged to change their management strategy, but cannot because they are trapped in a lock-in situation due to a long history of control-based management. 


\section{The way Forward}

Policymakers often consider uncertainty as a problem that complicates the decision-making process. As coping with uncertainty is unavoidable in river management, policymakers should become better at employing different strategies to cope with uncertainties and arrive at decisions that are accepted by all stakeholders. For example, an unpredictable situation (ontological uncertainty) requires a different course of action from one that is characterized by different views on the most valuable outcome (ambiguity). In the first case, the policymaker should either accept that he or she cannot know more, define scenarios with possible outcomes or quantify the uncertainty. In the second case, gathering technical information will not improve the interpretation of the problem and other strategies can be followed to find common collective goals or redefine the problem definitions to embrace the existing differences in views (Brugnach et al. 2011). Thus, different types of uncertainty require different actions. In this section, we illustrate the concepts from literature that were introduced in section 2 with several real-life examples to provide policymakers with a concrete step-wise strategy to cope with uncertainty.

\subsection{Identify Uncertainties}

The first step if confronted with uncertainty in policymaking is to identify the uncertainties in the policymaking process (Van der Keur et al. 2008). Analysing the assumptions of management plans is the start of most flexible planning strategies (e.g. Walker et al. 2013; Haasnoot et al. 2013). When identifying uncertainties, it is of crucial importance to consider all types of uncertainty. This is challenging, but vital to the reliability of the management plan. In doing so, the focus should be on analysing the uncertainties that have the largest consequences for the success (so-called 'load-bearing' assumptions; Walker et al. 2013). The use of an uncertainty typology (Section 2.1) raises awareness of the full range of possible uncertainties. More detailed typologies are available that might aid the identification (e.g. Brugnach et al. 2008; Warmink et al. 2010). During identification it is essential to also include ambiguities in the analysis and not only consider an improved understanding of the usually complex system (Hommes et al. 2009b; Merz et al. 2015). A commonly used method of expressing uncertainty and risk in terms of economic losses does not express whether an event is really vicious to a stakeholder (Merz et al. 2015) showing the need for a broader range of uncertainties.

Identification of uncertainties that may lead to harmful consequences requires both an estimate of the potential to occur and the degree of the consequences. Expert elicitation can be used to identify the uncertainties, but it requires awareness of the full range of uncertainties (Warmink et al. 2011). Merz et al. (2015) recommend to let imagination play a role in the definition of scenarios and include independent persons for "de-biasing the flawed human mind" in the assessment to also identify uncertainties beyond the obvious.

In the past decades, several strategies to cope with uncertainty in policymaking have been developed and applied (e.g. Allan and Curtis 2005; Pahl-Wostl et al. 2007; Walker et al. 2013; Haasnoot et al. 2013; Thissen et al. 2017; Furlong et al. 2017). Refsgaard et al. (2007), Brugnach et al. (2011), Bond et al. (2015) and Merz et al. (2015) provide different sets of strategies to cope with uncertainty. However, note that these strategies mainly assume independent uncertainties, while uncertainties are interrelated (Van den Hoek et al. 2014). This implies that if the selected uncertainty strategy does not work, alternative strategies, possibly targeted at other uncertainties, can be followed (Van den Hoek et al. 2014), which offers the opportunity to adapt, but requires flexibility and 
learning. This shows that coping with uncertainty requires another way of thinking and continuous adaptation.

Uncertainties are influenced by people's roles and perceptions and therefore may require changes in policymaking processes and organizations. The identification of the source of uncertainty leads to possible strategies to solve the uncertainty. However, there is not an optimal strategy and therefore, different strategies need to be pursued, including reflection on the organization of the policymaking process itself. Develop a shared understanding within a group of stakeholders about policy decisions requires co-creation of a shared knowledge base to reduce social uncertainties by contextualizing the solutions and therefore may require changes in the policymaking process.

\subsection{Implementing Changes in the Policymaking Process}

Once the major sources of uncertainty have been identified, actions, frames or governance structures might need to be changed to better cope with uncertainty (see Fig. 1). Only changing actions (single-loop learning) may be insufficient and double-loop or even triple-loop learning may be needed.

An example in which river management moved from single-loop to double-loop learning can be found in the Netherlands. Until recently, river management was characterized here by a business as usual strategy. Every five years, the hydraulic boundary conditions and prescribed test instruments (e.g. mathematical models) were updated to include new knowledge about the state of the system, thereby reducing epistemic and quantifying ontological uncertainty. In 2007, a policy change was initiated following the establishment of the Delta Committee. This committee consists of politicians, policymakers and scientists and is mandated to prepare an advice on the protection of the Netherlands given the consequences of climate change (DC 2008). Their advice reflects the need for reframing or second-loop learning. They advised, amongst others, on how to cope with uncertainty due to climate change, which would significantly increase flood risks and concluded that it would require a substantial effort to account for climate change in the current policy and recommended a change from a reaction policy towards anticipation. To achieve this goal, the procedure of the cost-benefit analysis to compute the legal flood norms was adapted from an exceedance probability strategy to a riskbased strategy (VNK 2014), which required changing the underlying principles. This adaptation required reflective analyses, adaptations of the law and changes to the governance system, from policymakers to executing agencies. However, the underlying perception that flood protection is based on probabilities and is the responsibility of the national government remained (DP 2015). Instead of using only prescribed conservative estimates, this new riskbased policy enables the explicit computation of flooding probabilities (VNK 2014). Consequently, there is also more space for adopting other strategies to cope with uncertainty. Executing this second-loop change was therefore a first step to reduce conservatism and moving away from the lock-in situation.

An example of a case where a third-loop change was incipient is the Guadiana basin. The Upper-Guadiana basin is located in Spain, which faces climatic induced droughts. The water management challenge of the responsible water authority was that there were severe droughts, which led to water shortage for farmers. However, uncertainty about the cause of the water shortage complicated policymaking. In this case, the solution to the problem was initially sought in a control-based policy, which proved to be ineffective (Martínez-Santos et al. 2008). 
A key challenge for the Guadiana regional and national water authorities who were dealing with drought issues was that both the availability of water and the underlying causes were uncertain (Brugnach et al. 2008). The amount of available water was difficult to determine because of the physical characteristics of the system, changes in climate and an uncontrolled groundwater abstraction. The initial response of the authorities was to reduce the epistemic uncertainty by improved control of water abstractions (e.g. setting a water quota). However, this solution did not take into consideration the ambiguities that existed among farmers, environmental groups and river basin authorities, resulting in social unrest and an unsustainable use of groundwater resources. Instead, other strategies had to be applied, based on negotiations and learning were able to cope with the disagreements among stakeholders (Brugnach et al. 2011). This exercise resulted in a more comprehensive understanding of the problem by all stakeholders and led to the development of the Upper Guadiana Plan, a legally binding instrument that served to agree in how to collectively manage the basin.

The Guadiana case illustrates a situation in which first-loop action did not contribute to the solution, because it missed to address important uncertainties. Instead, a thorough reflection on the uncertainties, where the ambiguities were also acknowledged, led to a more comprehensive view on what the problematic issues were and whose responsibilities. This process resulted in new legal agreements about how to manage the basin. Although uncertainty was still present, it became accepted and more clearly handled.

\subsection{Strategies and Actions for Policymakers}

In the control-based paradigm, uncertainty is perceived by policymakers as something unwanted that needs to be dealt with and preferably eliminated. For policies that are characterized by a lockin situation, lessons can be learnt from the examples presented in the previous sections. Uncertainty should be seen as a strength, not as a weakness. An analysis of the uncertainties in the policymaking process can be used to develop better and more flexible management strategies as shown in the examples in the previous sections. A more comprehensive overview of the uncertainties enables the development of more robust policies with less negative surprises. If more possible outcomes are considered using e.g. scenario analysis (not necessarily analysed in detail), future uncertainties may be anticipated upon (Merz et al. 2015). Additionally, early identification and communication of uncertainties may prevent other uncertainties from arising (due to interrelation) and hence may contribute to easier acceptance by stakeholders.

Coping with uncertainty is often considered by policymakers as their responsibility. However, uncertainty is relevant to all stakeholders and, therefore, also their responsibility. Third-loop learning might be needed to achieve such a shared responsibility in policymaking. The Guadiana case showed that sharing the responsibility with the stakeholders led to a more successful management strategy, where uncertainties complicated the policymaking less and were more accepted. Although, the Guadiana example was a local case and only showed that this strategy worked on a small scale, it illustrates the possible benefits of a paradigm shift also on a national level. Developing a sense of co-responsibility between the government and the various stakeholders can increase the self-resilience of the population. In a situation with high protection levels there is less motivation for the public to prepare against floods. However, a shared responsibility may yield the choice to accept a higher flood risk instead of raising dikes, which reduces social uncertainties.

The lock-in situation showed that having (very) high protection standards is not always beneficial. It results in a policy process, where decisions tend to increase these standards. In the 
UK, the Environmental Agency developed a new advice on adaptation to climate change for flood protection (EA 2011). This advice recommends a flexible strategy, based on taking action when certain trigger points are encountered as a way to manage uncertainties associated with climate change. Also in the USA (CEQ 2010) and The Netherlands (DC 2008), the national governments outlined recommendations that climate change effects should be anticipated by e.g. land use planning, which is a first step towards more adaptive management. These examples illustrate the tendency of countries with a control-based management towards more flexible and adaptive strategies. Other countries could learn from this and should not aim for a policy largely based on control.

\subsection{Improving Uncertainty Management Strategy}

In uncertainty management, interventions should be approached as flexible processes in which goals and means are adapted to changing circumstances, new insights and other emergent dynamics (Leeuwis and Van den Ban 2004). It recognizes the importance of learning and the need to adapt strategies and goals during the process in response to new information (Pahl-Wostl et al. 2007). Although reducing epistemic uncertainty by improving knowledge is essential, firstloop learning does not always solve the uncertainty issue. It might cause too much attention to uncertainty and create superfluous knowledge (Hommes et al. 2009b). Only adopting an adaptive management paradigm is not sufficient, as it does not inherently comprises reflection. Moving towards a more flexible policy may require a paradigm shift from controlling the uncertainties (or at least trying to do so) towards being truly flexible and adaptive, which inherently implies to let go of control. Similarly, other authors, using different terminology, also emphasize the need for a shift from control-based management (also referred to as technocratic or rational planning) towards including the social and political dimensions (referred to as sociocratic planning) (e.g. Furlong et al. 2016). Note again that we consider 'adaptive' to be a paradigm that prevents stakeholders to get into a lock-in situation, rather than stating that it always leads to a solution. We consider being adaptive, as focussing on continuous improvement.

Keeping an open mind requires being reflective towards oneself and the own organization. The task to be reflective is not easy (Weick et al. 2005). People often handle the unexpected by normalizing it out of existence (e.g. Merz et al. 2015). One issue here is that the organization of the workflow often affects the way people think (Weick et al. 2005), while reflection requires people to analyse their own workflow. Both in the Guadiana and Romania examples, external, independent actors studied the policy process and elicited the opinions of stakeholders. They concluded, based on various interviews with stakeholders, that the motivation of stakeholders did not match the motivation of the project plans. This shows that unaffected third parties are needed to identify uncertainties to avoid malicious surprises. Huitema and Meijerink (2010) argued that policy changes are often initiated after an existing paradigm has been put to the test by the occurrence of disastrous "shock" events, such as a flood. However, in an ideal world, disasters should not be needed to initiate policy changes.

\section{Conclusions}

In this paper we present a holistic perspective on coping with uncertainty that integrates social and natural scientists' perspectives on uncertainty and learning theories. The policymaker's final aim is that their management plans are effective, efficient and feasible and that 
uncertainty in the policy-making process is accepted by all stakeholders, so that uncertainty does not limited the implementation. Here, we have argued that coping with uncertainty may require paradigm shifts that can only be achieved through social and organisational learning.

We conclude that:

1. In policymaking, uncertainties are unavoidable, but are often also receiving too much or too little attention. Balancing the social and technical uncertainties is essential for a successful uncertainty management strategy. A proper identification of uncertainties in the policymaking process aids in getting this balance right and to raise awareness and support for policy plans.

2. In modern industrial countries with a history of a control-based management, uncertainties are typically dealt with by being conservative. This may lead to a lock-in situation, in which policymakers aim at reducing natural and technical uncertainties. Our examples illustrated that striving for certainty by gathering more and better knowledge is not always the optimal strategy to cope with uncertainty. We used the learning cycle concept to guide organisational change, paradigm shifts and reflection on people's frames and perceptions, which are essential components in coping with uncertainties.

3. We argue that better coping with uncertainty requires flexibility of the policymakers, being reflective about organisational processes, and changing perspectives of scientists, policymakers and other stakeholders to co-create a shared knowledge base. Sharing responsibilities is presented as an example of a transformation in the Guadiana basin, leading to better implementation of policy and less uncertainty. These components are essential to improve coping with uncertainty in policymaking, but are currently not always included.

Shifting policy towards adaptive management is increasingly advocated as a suitable framework to cope with uncertainty, but also in its application the entire uncertainty space needs to be considered and it requires an open mind to prevent surprises and disasters. We have argued that 'management' is sometimes confused with 'learning by doing'. No strategy is fully adaptive, but should focus on continuous improvements and try to prevent to get into a lock-in situation. Achieving this requires reflection, learning and flexibility of policymakers and their organisation. We presented several tools to raise awareness, enhance learning and examples that show its potential.

Acknowledgements We want to thank Rijkswaterstaat for the organisation of the workshop of the Netherlands Centre for River Studies (NCR), and all participants for their constructive input and discussion. Dr. Vinke-de Kruijf received financial support of a Marie-Curie Intra-European Fellowship grant within the European Community Framework Programme (PIEF-GA-2012-326268). This research has benefited from cooperation within the network of the Netherlands Centre for River studies.

Open Access This article is distributed under the terms of the Creative Commons Attribution 4.0 International License (http://creativecommons.org/licenses/by/4.0/), which permits unrestricted use, distribution, and reproduction in any medium, provided you give appropriate credit to the original author(s) and the source, provide a link to the Creative Commons license, and indicate if changes were made.

\section{References}

Allan C, Curtis A (2005) Nipped in the bud: why regional scale adaptive management is not blooming. Environ Manag 36(3):414-425. doi:10.1007/s00267-004-0244-1

Allan C, Curtis A, Stankey G, Shindler B (2008) Adaptive management and watersheds: a social science perspective. J Am Water Resour Assoc 44(1):166-174

Allan C, Xia J, Pahl-Wostl C (2013) Climate change and water security: challenges for adaptive water management. Curr Opin Environ Sustain 5(6):625-632. doi:10.1016/j.cosust.2013.09.004 
Argyris C, Schön D (1978) Organizational learning: a theory of action perspective. Addison Wesley, Reading

Ascough JC II, Maier HR, Ravalico JK, Strudley MW (2008) Future research challenges for incorporation of uncertainty in environmental and ecological decision-making. Ecol Model 219: 383-399. doi:10.1016/j.ecolmodel.2008.07.015

Bond A, Morrison-Saunders A, Gunn JA, Pope J, Retief F (2015) Managing uncertainty, ambiguity and ignorance in impact assessment by embedding evolutionary resilience, participatory modelling and adaptive management. J Environ Manag 151:97-104. doi:10.1016/j.jenvman.2014.12.030

Brugnach M, Dewulf A, Pahl-Wostl C, Taillieu T (2008) Toward a relational concept of uncertainty: about knowing too little, knowing too differently, and accepting not to know. Ecol Soc 13(2):30 http://www. ecologyandsociety.org/vol13/iss2/art30/

Brugnach M, Dewulf A, Henriksen H, Van der Keur P (2011) More is not always better: coping with ambiguity in natural resources management. J Environ Manag 92(1):78-84. doi:10.1016/j.jenvman.2010.08.029

CEQ (2010) Progress report of the interagency climate change adaptation task force: recommended actions in support of a national climate change adaptation strategy. The White House Council on Environmental Quality. http://www.whitehouse.gov/sites/default/files/microsites/ceq/InteragencyClimate-Change-Adaptation-Progress-Report.pdf. Accessed 25 Jan 2016

Collins K, Ison R (2009) Editorial: living with environmental change: adaptation as social learning. Env Pol Gov 19(6):351-357. doi:10.1002/eet.520

DC (2008) Working together with water, a living land builds for its future. Findings of the Deltacommissie 2008

De Bruijn H, Leijten M (2007) Megaprojects and contested information. Transport Plan Techn 30(1):49-69. doi: $10.1080 / 03081060701208050$

Dessai S, Hulme M (2007) Assessing the robustness of adaptation decisions to climate change uncertainties: a case study on water resources management in the east of England. Glob Environ Change 17(1):59-72. doi:10.1016/j.gloenvcha.2006.11.005

DP (2015) Delta programme 2015, working on the Delta, the decisions to keep the Netherlands safe and livable. Ministry of Infrastructure and the Environment, The Netherlands

EA (2011) Adapting to climate change: advice for flood and coastal erosion risk management authorities. The Environment Agency, United Kingdom

Failing L, Gregory R, Higgins P (2013) Science, uncertainty, and values in ecological restoration: a case study in structured decision-making and adaptive management. Restor Ecol 21(4):422-430. doi:10.1111/j.1526-100 X.2012.00919.x

Furlong C, Silva SD, Guthrie L, Considine R (2016) Developing a water infrastructure planning framework for the complex modern planning environment. Util Policy 38:1-10. doi:10.1016/j.jup.2015.11.002

Furlong C, Brotchie R, Considine R, Finlayson G, Guthrie L (2017) Key concepts for integrated urban water management infrastructure planning: lessons from Melbourne. Util Policy 45:84-96. doi:10.1016/j. jup.2017.02.004

Gleick PH (2000) The changing water paradigm, a look at twenty-first century water resources development. Water Int 25(1):127-138

Haasnoot M, Kwakkel JH, Walker WE, Ter Maat J (2013) Dynamic adaptive policy pathways: a method for crafting robust decisions for a deeply uncertain world. Glob Environ Change 23(2): 485-498. doi:10.1016/j.gloenvcha.2012.12.006

Hargrove R (2002) Masterful coaching, Revised edn. Jossey-Bass/Pfeiffer, Wiley, USA

Hisschemöller M, Hoppe R (2001) Coping with intractable controversies: the case for problem structuring in policy design and analysis. In: Hisschemöller et al. (Eds) knowledge, power, and participation in environmental policy analysis. Transaction, New Brunswick and London, pp 47-72

Hommes S, Vinke-de Kruijf J, Otter HS, Bouma G (2009a) Knowledge and perceptions in participatory policy processes: lessons from the Delta-region in the Netherlands. Water Resour Manag 23(8):1641-1663. doi:10.1007/s11269-008-9345-6

Hommes S, Hulscher SJMH, Mulder JPM, Otter HS, Bressers JTA (2009b) Role of knowledge and perceptions in the impact assessment for the extension of Mainport Rotterdam. Mar Policy 33:146-155. doi:10.1016/j. marpol.2008.05.006

Huitema D, Meijerink S (2010) Realizing water transitions. The role of policy entrepreneurs in water policy change. Ecol Soc 15(2):26. http://www.ecologyandsociety.org/vol15/iss2/art26/

IWR (2011) Flood risk management approaches, as being practiced in Japan, Netherlands, United Kingdom and United States. (IWR report No: 2011-R-08) Institute for Water Resources, USACE, USA

Koppenjan J, Klijn E-H (2004) Managing uncertainty in networks. Routledge, London

Lawrence J, Reisinger A, Mullan B, Jackson B (2013) Exploring climate change uncertainties to support adaptive management of changing flood-risk. Environ Sci Pol 33:133-142. doi:10.1016/j.envsci.2013.05.008

Leeuwis C, Van den Ban AW (2004) Communication for rural innovation: rethinking agricultural extension. Blackwell Science, Oxford 
Martínez-Santos P, Llamas MR, Martínez-Alfaro PE (2008) Vulnerability assessment of groundwater resources: a modelling-based approach to the Mancha occidental aquifer, Spain. Environ Model Softw 23(9):11451162. doi:10.1016/j.envsoft.2007.12.003

Merz B, Vorogushyn S, Lall U, Viglione A, Blöschl G (2015) Charting unknown waters - on the role of surprise in flood risk assessment and management. Water Resour Res 51(8):6399-6416. doi:10.1002/2015WR017464

Pahl-Wostl C (2009) A conceptual framework for analysing adaptive capacity and multi-level learning processes in resource governance regimes. Glob Environ Change 19(3):354-365. doi:10.1016/j. gloenvcha.2009.06.001

Pahl-Wostl C, Craps M, Dewulf A, Mostert E, Tabara D, Taillieu T (2007) Social learning and water resources management. Ecol Soc 12(2):5 http://www.ecologyandsociety.org/vol12/iss2/art5/

Pahl-Wostl C, Jeffrey P, Isendahl N, Brugnach M (2011) Maturing the new water management paradigm: progress from aspiration to practice. Water Resour Manag 25:837-856. doi:10.1007/s11269-010-9729-2

Pappenberger F, Beven KJ (2006) Ignorance is bliss: or seven reasons not to use uncertainty analysis. Water Resour Res 42:W05302. doi:10.1029/2005WR004820

Refsgaard JC, Van der Sluijs JP, Lajer-Hojberg A, Vanrolleghem PA (2007) Uncertainty in the environmental modelling process: a framework and guidance. Environ Model Softw 22(11):1543-1556

Stirling A (2010) Keep it complex. Nature 468(7327):1029-1031. doi:10.1038/4681029

Thissen W, Kwakkel J, Mens MJP, Van der Sluijs JP, Stemberger S, Wardekker A, Wildschut D (2017) Dealing with uncertainty in fresh water supply: experiences in the Netherlands. Water Resour Manag 31(2):703-725. doi:10.1007/s11269-015-1198-1

Tillman D, Larsen T, Pahl-Wostl C, Gujer W (1999) Application of models in water management modeling the actors in water supply systems. Water Sci Technol 39(4):203-211. doi:10.1016/S0273-1223(99)00055-4

Van Asselt MBA, Rotmans J (1996) Uncertainty in perspective. Glob Environ Change 6(2):121-157

Van Asselt MBA, Rotmans J (2002) Uncertainty in integrated assessment modelling. Clim Chang 54(1):75-105. doi:10.1023/A:1015783803445

Van de Riet AWT (2003) Policy analysis in multi-actor policy settings: navigating between negotiated nonsense and superfluous knowledge. Dissertation, Technical University of Delft

Van den Hoek RE, Brugnach M, Mulder JPM, Hoekstra AY (2014) Analysing the cascades of uncertainty in flood defence projects: how "not knowing enough" is related to "knowing differently". Glob Environ Change 24:373-388. doi:10.1016/j.gloenvcha.2013.11.008

Van der Keur P, Henriksen HJ, Refsgaard JC, Brugnach M, Pahl-Wostl C, Dewulf A, Buiteveld H (2008) Identification of major sources of uncertainty in current IWRM practice. Illustrated for the Rhine basin. Water Resour Manag 22(11):1677-1708. doi:10.1007/s11269-008-9248-6

Van der Keur P, Van Bers C, Henriksen HJ et al (2016) Identification and analysis of uncertainty in disaster risk reduction and climate change adaptation in south and Southeast Asia. Int J Disaster Risk Reduct 16:208-214

Vinke-de Kruijf J, Augustijn DCM, Bressers JTA (2012) Evaluation of policy transfer interventions: lessons from a Dutch-Romanian planning project. J Environ Policy Plan 14(2):139-160

Vinke-de Kruijf J, Bressers HTA, Augustijn DCM (2015) Integrated Management of the Lower Danube River: experiences with the application of Dutch policy concepts and interactive planning methods. In: Iordachi C, Van Assche K (eds) The biopolitics of the Danube Delta: nature. Policies, Lexington Books, Lanham, History, pp 373402

VNK (2014) The national flood risk analysis for the Netherlands, final report. Rijkswaterstaat VNK Project Office, The Netherlands

Walker WE, Harremoës P, Rotmans J, Van der Sluijs JP, Van Asselt MBA, Janssen P, Krayer von Kraus MP (2003) Defining uncertainty, a conceptual basis for uncertainty management in model-based decision support. Integr Assess 4(1):5-17

Walker WE, Haasnoot M, Kwakkel JH (2013) Adapt or perish: a review of planning approaches for adaptation under deep uncertainty. Sustain 5(3):955-979. doi:10.3390/su5030955

Walters CJ (2007) Is adaptive management helping to solve fisheries problems? Ambio 36(4):304-307

Warmink JJ, Janssen JAEB, Booij MJ, Krol M (2010) Identification and classification of uncertainties in the application of environmental models. Environ Model Softw 25(12):1518-1527. doi:10.1016/j. envsoft.2010.04.011

Warmink JJ, Van der Klis H, Booij MJ, Hulscher SJMH (2011) Identification and quantification of uncertainties in a hydrodynamic river model using expert opinions. J Water Resour Manag 25(2):601-622. doi:10.1007 /s11269-010-9716-7

Weick KE, Sutcliffe KM, Obstfeld D (2005) Organizing and the process of Sensemaking. Organ Sci 16(4):409421. doi:10.1287/orsc.1050.0133

Wyborn C (2015) Co-productive governance: a relational framework for adaptive governance. Glob Environ Change 30:56-67. doi:10.1016/j.gloenvcha.2014.10.009 